\title{
Controlled comparison of milnacipran and fluoxetine in major depression
}

Marc Ansseau $^{1}$, Patrick Papart
Schittecatte $^{5}$, Benoît Troisfontaines
${ }^{2}$, Franz Bartholome $^{3}$, Michel Bataille
${ }^{4}$, Gérard Charles Luc Evrard $^{11}$, André De Nayer ${ }^{11}$, Pierre Krémer ${ }^{11}$, Claudine Mertens ${ }^{12}$, Christiane Serre ${ }^{13}$

\author{
${ }^{1}$ Psychiatric Unit, C. H. U. du Sart Tilman, B-4000 Liège, Belgium \\ ${ }^{2}$ Clinique Saint-Vincent, B-4000 Rocourt, Belgium \\ ${ }^{3}$ Clinique Saint-Joseph, B-4000 Liège, Belgium \\ ${ }^{4} \mathrm{~B}-4000$ Liège, \\ ${ }^{5}$ Hôpital Vincent Van Gogh, B-6030 Marchienne-au-Pont, Belgium \\ ${ }^{6}$ Centre Hospitalier de Sainte-Ode, B-6680 Sainte-Ode, Belgium \\ ${ }^{7}$ Hôpital du Petit Bourgogne, B-4000 Liège, Belgium \\ ${ }^{8}$ Neuropsychiatrische Kliniek Sint Camillus, B-9051 Sint-Denijs-Westrem, Belgium \\ ${ }^{9}$ Centre Médical de Serbie, B-4000 Liège, Belgium \\ ${ }^{10}$ Clinique de la Mutualité , B-4800 Verviers, Belgium \\ ${ }^{11}$ Clinique Sainte-Thérèse, B-6061 Montignies-sur-Sambre, Belgium \\ ${ }_{12}$ Psychiatrische Centra, B-9940 Evergem-Sleidinge, Belgium, \\ ${ }^{13}$ Laboratoires Pierre Fabre Médicament, F-81106 Castres, France
}

Received December 30, 1992/Final version May 28, 1993

\begin{abstract}
The efficacy and the tolerance of milnacipran $(100 \mathrm{mg} /$ day), a second generation antidepressant which equipotently inhibits both noradrenaline and serotonin reuptake, was compared to fluoxetine $(20 \mathrm{mg} /$ day), a selective serotonin reuptake inhibitor, in two parallel groups of, respectively, 97 and 93 major depressive outpatients. The duration of the study was 6 weeks, with assessments every 2 weeks by means of the Montgomery and Asberg depression scale (MADRS), the Hamilton depression scale, the clinical global impressions (CGI), and a checklist of symptoms and side-effects. Results showed significant superiority of fluoxetine over milnacipran on most rating instruments: MADRS $(P=0.01)$ including five individual items, Hamilton depression scale $(P=0.002)$ including ten individual items, CGI of severity $(P=0.01)$ and therapeutical index $(P=0.002)$. On visual analogue scales assessing the clinical profile of the compounds, fluoxetine was rated as exhibiting more psychostimulating activity than milnacipran $(P=0.0008)$. The tolerance of the two antidepressants was very similar, with the exception of symptoms of dizziness which were more frequently reported with milnacipran $(P=0.01)$. These differences in efficacy favoring fluoxetine could result from the selection of a dose of milnacipran below the optimal therapeutic dose for this type of psychiatric patients or to the administration of the compounds in single daily intakes, whereas milnacipran possesses a plasma elimination half-life of only $7 \mathrm{~h}$.
\end{abstract}

Correspondence to: M. Ansseau
Key words: Milnacipran - Fluoxetine - Antidepressant - Major depression - Noradrenaline - Serotonin

The classical biochemical hypothesis of major depression posits a functional deficit in noradrenergic and/or serotonergic central neurotransmission (Van Praag 1980a, b). Based on this theory, an antidepressant acting on both noradrenergic and serotonergic systems could exhibit a broader spectrum of efficacy than an antidepressant acting on a sole system (Van Praag 1984). Milnacipran (1-phenyl-1-diethyl-amino-carbonyl-2-amino-methylcyclopropane hydrochloride), a racemic drug, is a new antidepressant selected for its equipotent inhibition of noradrenaline and serotonin uptake and its lack of effect at any postsynaptic receptor (Moret et al. 1985). Its antidepressant efficacy has already been established as superior to placebo (Macher et al. 1989) and equivalent to reference tricyclics, particularly amitriptyline (Ansseau et al. 1989a, b) and clomipramine (Clerc et al. 1990). In all comparative studies, the tolerance of milnacipran was significantly better than tricyclics (Ansseau et al. 1989a, b; Clerc et al. 1990). Fluoxetine is a selective serotonin reuptake inhibitor antidepressant exhibiting efficacy similar to reference tricyclics but less anticholinergic side-effects (Benfield et al. 1986). Therefore, the purpose of the present study was to test if milnacipran, acting on both noradrenergic and serotonergic reuptake mechanisms, could exhibit a different spectrum of activity than fluoxetine, acting solely on serotonin reuptake processes. In addition, such comparative data involving "second generation" antidepressants are clearly needed in order to better define their particular profiles in terms of efficacy and tolerance (Benfield and Ward 1986). 


\section{Subjects and methods}

Design of the study. The study was performed between February 1990 and October 1991 in 16 Belgian centres used to collaboration and exhibiting excellent reliability in clinical rating (see affiliations). The trial used a double-blind design with two parallel groups of patients randomly assigned to milnacipran $100 \mathrm{mg} /$ day or fluoxetine $20 \mathrm{mg} /$ day. All treatments were administered as single evening intakes. The active period was preceded by a wash-out period of 4-7 days on placebo.

Somatic treatments could be pursued throughout the study period, except antiarrhythmic drugs, digitalis drugs, alpha-blocking antihypertensive drugs and anorexigens which had to be discontinued at least 1 week before the study and beta-blockers which had to be used at a stable dose for at least 2 months before the study. The association of psychotropic drugs was excluded throughout the study period, except for the occasional intake of low dose lorazepam as anxiolytic and/or hypnotic. The duration of the study was 6 weeks, with assessments every 2 weeks. Compliance was ensured by drug count; plasma levels were not determined. The trial was monitored according to all principles of European and US "good clinical practice" (Ministère des Affaires Sociales et de l'Emploi 1987; Mathieu 1990).
Subjects. A total of 190 outpatients were included in the study: 97 in the milnacipran group and 93 in the fluoxetine group. Patients were 47 males and 143 females, aged from 19 to 68 years, with a mean age (SD) of 44.9 (11.2) years. All subjects were depressive outpatients who fulfilled DSM-III-R criteria for a major depressive episode (American Psychiatric Association 1987) and had a score of at least 25 on the Montgomery and Asberg Depression Rating Scale (MADRS) (Montgomery and Asberg 1979), a score of at least 4 for the severity of illness as defined by the clinical global impressions (CGI) (Guy 1976), and a score on the Raskin scale for depression higher than the score on the Covi scale for anxiety (Raskin et al. 1967; Covi et al. 1979). Initial scores ranged from 25 to 47 with a mean (SD) of 33.6 (4.7) on the MADRS and from 17 to 49 with a mean (SD) of 31.5 (5.9) on the 24-item Hamilton depression scale (Hamilton 1960)

Patients presenting serious or uncontrolled medical illness (renal, hepatic, respiratory and cardiac failure) were excluded from the study. Moreover, patients exhibiting major anxiety, agitation, or suicide risk, resistance during the current episode to at least two antidepressants prescribed at an effective dose during at least 3 weeks, substance abuse or dependence were also excluded, as well as patients taking lithium, a monoamine oxidase antidepressant, or a long acting neuroleptic during the previous month or requiring the

Table 1. Demographic and clinical characteristics of the sample

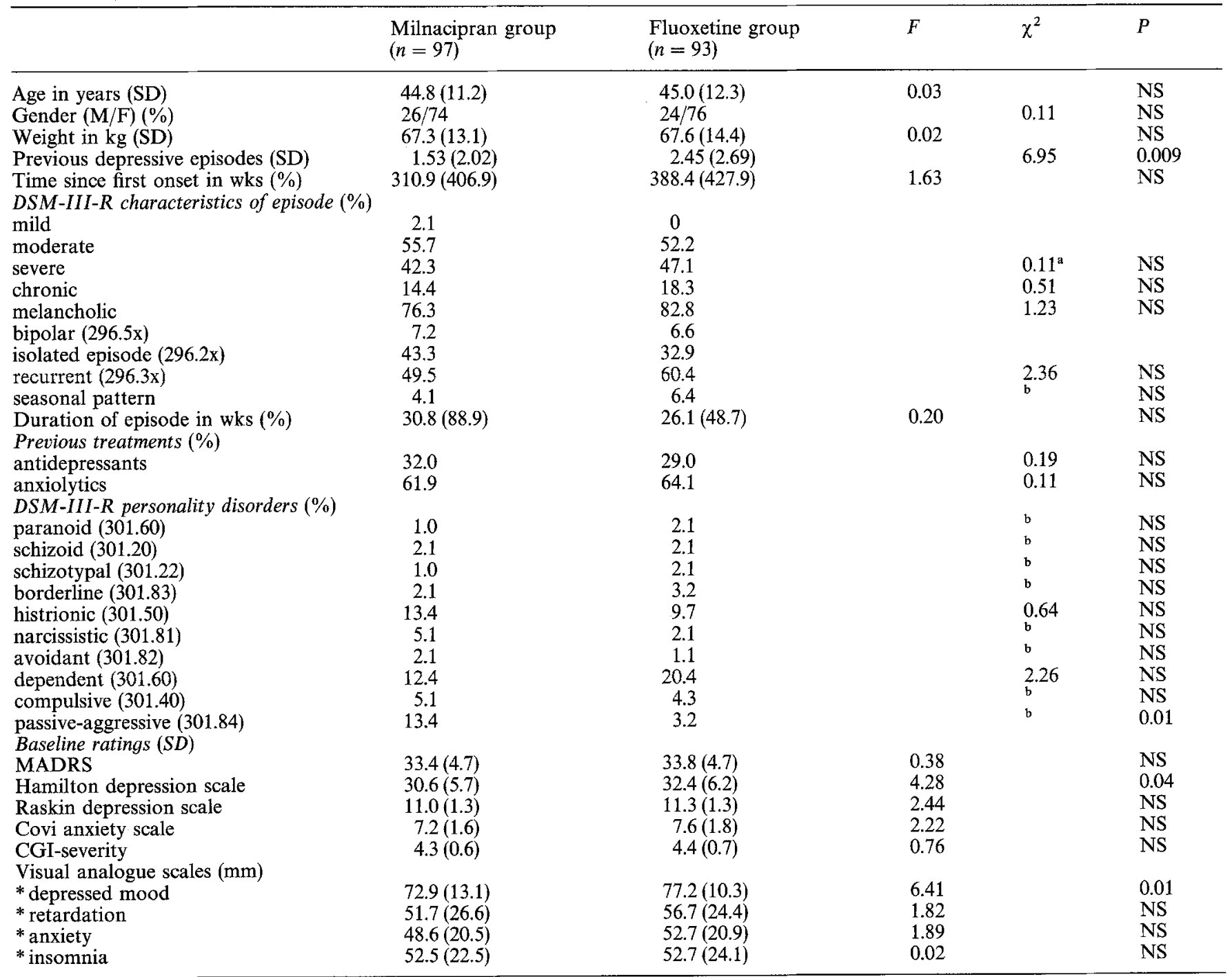

a Contingency coefficient;

${ }^{\mathrm{b}}$ Fisher's exact test 
current intake of a neuroleptic or an anxiolytic or hypnotic drug other than lorazepam at low dose.

The main demographic and clinical characteristics of the patients are presented in Table 1. All data were comparable in the two treatment groups, except the number of previous depressive episodes and the baseline scores on the Hamilton depression scale and the visual analogue scale of depressed mood which were higher in the fluoxetine group, and the number of passive-aggressive personalities which was higher in the milnacipran group. The number of patients needed in each group was determined on the basis of expected differences of $20-30 \%$ on one or several parameters of activity and tolerance using tables comparing several means for two treatment groups with an alpha risk $=1 \%$ and a beta risk $=5 \%$ (Schwartz 1970). Finally, the protocol was approved by the Ethical Committee of the University of Liège Medical School, and patients were fully informed of the purpose of the study and gave their consent.

Assessments. Assessments were performed by means of the MADRS, the 24-item Hamilton depression scale, the CGI, and a checklist of symptoms and side-effects previously described which comprises specific items as well as reserve items related to behavior, central nervous system, autonomic nervous system and miscellaneous rated as 0 (none), 1 (mild), 2 (moderate) and 3(severe) (see Table 3) (Ansseau et al. 1989b, 1991). An open spontaneous notification of adverse events was also used. Moreover, the syndromic profile of each patient at inclusion was rated according to four $100-\mathrm{mm}$ visual analogue scales assessing depressed mood, psychomotor retardation, anxiety, and insomnia, and the clinical profile of the antidepressant of the end of the study was evaluated according to seven $100-\mathrm{mm}$ visual analogue scales assessing specifically the antidepressant, psychostimulating, anxiolytic, anticholinergic, sedative, hypotensive and digestive effects. These parameters were selected form a "star" model designed to compare the clinical characteristics of individual antidepressants (Ansseau et al. 1985). Weight was recorded and laboratory tests, including hepatic and renal balance-sheets, were carried out before inclusion and at the end of the treatment period.

Data analysis. Initially, the homogeneity of the two treatment groups was controlled, using one-way analysis of variance (ANOVA) or Chi-square statistics, the Fisher exact test or the contingency coefficient. All changes over time in ratings were assessed by multivariate ANOVAs with repeated measures using the intent to treat sample. An endpoint analysis was also performed but since the conclusions were similar, they are not reported in this paper. The levels of side-effects were compared between the two groups using Chi-square statistics, exact Fisher test, or contingency coefficients. All statistical procedures used a SAS package.

\section{Results}

\section{Dropouts}

A total of 41 patients $(21.6 \%)$ did not complete the 6-week study: $23(23.7 \%)$ in the milnacipran group and $18(19.3 \%)$ in the fluoxetine group $\left(\mathrm{Chi}^{2}=0.53, d f=1, P=\mathrm{NS}\right)$. The distributions of the reasons for dropouts were inefficacy $(n=7)$, adverse event $(n=4)$, inefficacy and adverse events $(n=2)$, intercurrent illness $(n=1)$, and lost to follow-up $(n=9)$ in the milnacipran group and inefficacy $(n=4)$, adverse events $(n=6)$, inefficacy and adverse events $(n=1)$, improvement $(n=2)$, intercurrent illness $(n=1)$, and lost to follow-up $(n=4)$ in the fluoxetine group, indicating significantly more dropouts for inefficacy and lost to follow-up in the milnacipran group (contingency coefficient $=0.31, P=0.05$ ).
Efficacy

MADRS. The changes over time on the MADRS in the two groups are displayed in Fig. 1. Fluoxetine exhibited significantly better antidepressant efficacy than milnacipran $(F=6.08, d f=1,149, P=0.01)$. Five items showed better improvement with fluoxetine as compared to milnacipran: apparent sadness $(P=0.002)$, expressed sadness $(P=0.03)$, inner tension $(P=0.02)$, decrease in sleep $(P=0.007)$ and pessimistic thoughts $(P=0.04)$. The percentages of treatment responders, as defined by an improvement of at least $50 \%$ from baseline scores, were $4.7 \%$ after 2 weeks, $22.5 \%$ after 4 weeks and $40.0 \%$ after 6 weeks in the milnacipran group and, respectively, $15.0 \%, 32.9 \%$ and $61.3 \%$ in the fluoxetine group, showing significantly more responders with fluoxetine after $2(P=0.03)$ and 6 weeks $(P=0.009)$.

Hamilton depression scale. The changes over time on the Hamilton depression scale in the two treatment groups are presented in Fig. 2. Fluoxetine exhibited a significantly

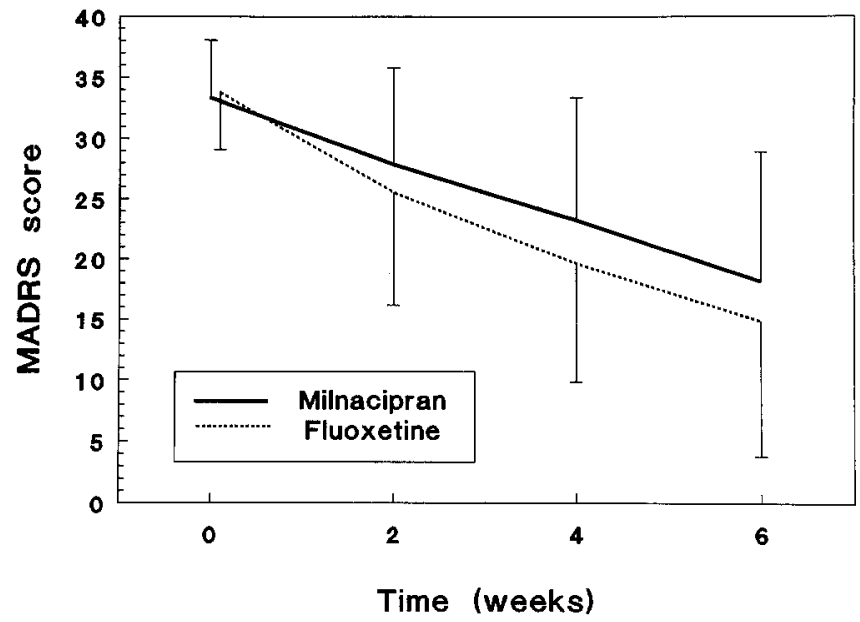

Fig. 1. Changes over time in mean scores $( \pm$ SD) on the MADRS among patients treated by milnacipran $100 \mathrm{mg}$ /day or fluoxetine $20 \mathrm{mg} /$ day

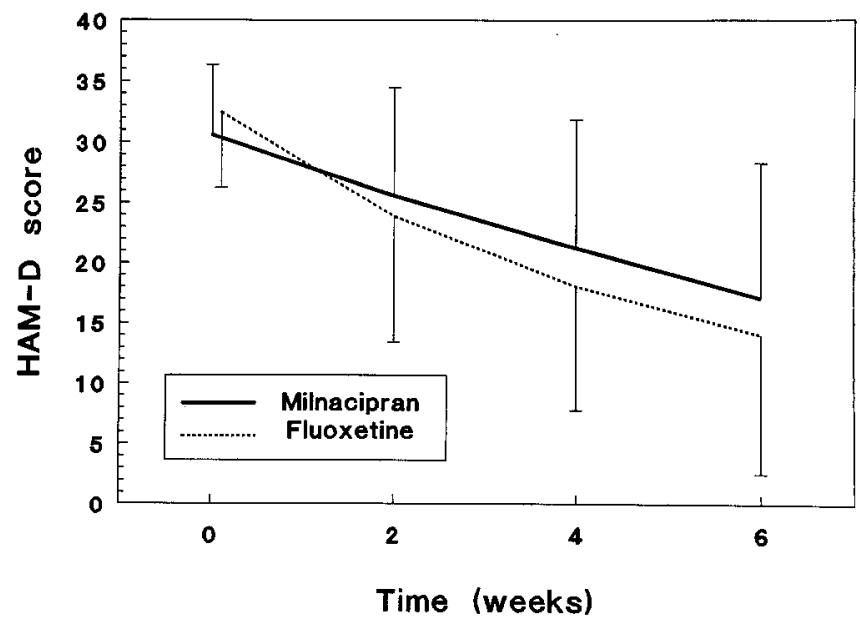

Fig. 2. Changes over time in mean scores $( \pm S D)$ on the Hamilton depression scale (HAM-D) among patients treated by milnacipran $100 \mathrm{mg} /$ day or fluoxetine $20 \mathrm{mg} /$ day 
better antidepressant effect than milnacipran $(F=10.02$, $d f=1,149, P=0.002$ ). Ten items exhibited a better improvement with fluoxetine as compared to milnacipran: depressed mood $(P=0.01)$, middle insomnia $(P=0.03)$, retardation $(P=0.03)$, psychic anxiety $(P=0.02)$, somatic anxiety $(P=0.03)$, gastrointestinal symptoms $(P=0.04)$ genital symptoms $(P=0.001)$, helplessness $(P=0.04)$, hopelessness $(P=0.03)$ and worthlessness $(P=0.03)$.

CGI. The changes over time on the CGI in the two treatment groups are presented in Table 2. The CGI related to the severity of illness exhibited a significantly better outcome with fluoxetine as compared to milnacip$\operatorname{ran}(F=6.71, d f=1,150, P=0.01)$. The global improvement did not exhibit a significant difference in outcome between the treatment groups $(F=3.20, d f=1.150$, $P=0.08$ ). In contrast, the efficacy index showed a better result with fluoxetine as compared to milnacipran $(F=9.67, d f=1,150, P=0.002)$.

Visual analogue scales. The mean ratings of the clinical profile of the antidepressant on visual analogue scales are presented in Table 3 . The only significant difference was related to the psychostimulating activity where fluoxetine obtained better scores than milnacipran $(P=0.0008)$.

Global assessments. The global results of the treatment by the investigator were rated as excellent in $19.3 \%$ of the cases, good in $24.7 \%$, moderate in $27.9 \%$, absent in $20.4 \%$ and negative in $7.5 \%$ with milnacipran and excellent in $41.6 \%$ of cases, good in $19.1 \%$, moderate in $14.6 \%$, absent in $15.7 \%$ and negative in $9.0 \%$ with fluoxetine, indicating significantly better outcome with fluoxetine $\left(\mathrm{Chi}^{2}=5.57\right.$, $d f=1, P=0.02$ ). The same ratings performed by the patient him/herself yielded $22.2 \%$ excellent, $15.6 \%$ good, $27.8 \%$ moderate, $24.4 \%$ absent and $10.0 \%$ negative re- sults with milnacipran and $32.6 \%$ excellent, $20.2 \%$ good, $16.9 \%$ moderate, $18.0 \%$ absent and $11.2 \%$ negative results with fluoxetine $\left(\mathrm{Chi}^{2}=1.9, d f=1, P=\mathrm{NS}\right)$. The treatment was prolonged in $50.0 \%$ of patients treated with milnacipran and $63.3 \%$ of the patients treated with fluoxetine $\left(\mathrm{Chi}^{2}=3.22, d f=1, P=0.07\right)$.

\section{Side-effects}

The comparison of the frequency of side-effects recorded on the checklist in the two treatment groups is presented in Table 4. The only significant difference was related to symptoms of dizziness which were more frequent with milnacipran. It should be noted that all three side-effects considered as serious appeared in the fluoxetine group: generalized cutaneous rash with asthmatiform syndrome after 4 days of treatment leading to hospitalization, and two suicide attempts after, respectively, 15 and 30 days of treatment. During the study, mean weight (SD) decreased from $67.30(13.1) \mathrm{kg}$ to $67.09(13.2) \mathrm{kg}$ in the milnacipran group and from $67.59(14.4) \mathrm{kg}$ to 67.19 (13.8) $\mathrm{kg}$ in the fluoxetine group, without any significant difference between the two treatments.

Laboratory tests did not reveal significant changes during the treatment period.

\section{Associated lorazepam}

The number of patients taking occasionally lorazepam did not differ between the two groups: $98 \%$ with milnacipran versus $97 \%$ with fluoxetine at baseline, $64 \%$ versus $61 \%$ after 2 weeks, $63 \%$ versus $63 \%$ after 4 weeks, and $61 \%$ versus $60 \%$ after 6 weeks.
Table 2. Comparison of efficacy on the CGI between milnacipran and fluoxetine (mean and SD)

\begin{tabular}{lllllll}
\hline & wk 0 & wk 2 & wk 4 & wk 6 & $F$ & $P$ \\
\hline CGI-severity & & & & & & \\
Milnacipran & $4.30(0.62)$ & $3.77(1.02)$ & $3.17(1.33)$ & $2.61(1.47)$ & & \\
Fluoxetine & $4.39(0.72)$ & $3.45(1.31)$ & $2.74(1.47)$ & $2.00(1.68)$ & 6.71 & 0.01 \\
CGI-improvement & & & & & & \\
Milnacipran & - & $2.23(1.09)$ & $1.80(1.29)$ & $1.37(1.27)$ & & \\
Fluoxetine & - & $1.97(1.65)$ & $1.37(1.37)$ & $1.03(1.51)$ & 3.20 & 0.08 \\
CGI-efficacy index & & $22.2(8.9)$ & $17.4(10.1)$ & $13.4(10.9)$ & & \\
Milnacipran & - & $18.0(9.9)$ & $12.8(8.8)$ & $9.2(10.6)$ & 9.67 & 0.002 \\
Fluoxetine & - & & &
\end{tabular}

Table 3. Clinical profile of antidepressant activity on visual analogue scales (mean and SD)

\begin{tabular}{lccc}
\hline & $\begin{array}{l}\text { Milnacipran } \\
n=97\end{array}$ & $\begin{array}{l}\text { Fluoxetine } \\
n=93\end{array}$ & $F$ \\
\hline Effect on depressed mood & $52.0(31.0)$ & $59.8(33.0)$ & 2.59 NS \\
Psychostimulating effect & $37.6(29.4)$ & $53.3(32.0)$ & 11.580 .0008 \\
Anxiolytic effect & $34.5(24.0)$ & $40.0(26.5)$ & $2.14 \mathrm{NS}$ \\
Anticholinergic effects & $7.9(14.8)$ & $6.8(8.6)$ & $0.38 \mathrm{NS}$ \\
Sedative effect & $10.5(16.0)$ & $10.5(15.0)$ & $0.00 \mathrm{NS}$ \\
Hypotensive effect & $6.6(9.0)$ & $7.1(12.4)$ & $0.11 \mathrm{NS}$ \\
Digestive effects & $26.1(28.5)$ & $20.3(24.0)$ & $2.10 \mathrm{NS}$ \\
\hline
\end{tabular}


Table 4. Comparison of the frequency of adverse events $(\%)$

\begin{tabular}{|c|c|c|c|c|}
\hline & $\begin{array}{l}\text { Milnacipran group } \\
n=97\end{array}$ & $\begin{array}{l}\text { Fluoxetine group } \\
n=93\end{array}$ & $\chi^{2}$ & $P$ \\
\hline \multicolumn{5}{|l|}{ Adverse behavior effect } \\
\hline insomnia & 5.1 & 7.5 & 0.45 & NS \\
\hline drowsiness & 2.1 & 2.1 & a & NS \\
\hline excitation-nervousness & 13.4 & 10.7 & 0.31 & NS \\
\hline depression & 0.0 & 1.1 & a & NS \\
\hline confusion & 1.0 & 0.0 & a & NS \\
\hline others & 0.0 & 2.1 & a & NS \\
\hline \multicolumn{5}{|l|}{ Central nervous system } \\
\hline rigidity & 1.0 & 0.0 & a & NS \\
\hline tremor & 6.2 & 5.4 & 0.06 & NS \\
\hline dystonic symptoms & 1.0 & 0.0 & a & NS \\
\hline akathisia & 2.1 & 4.3 & a & NS \\
\hline others & 0.0 & 1.1 & a & NS \\
\hline \multicolumn{5}{|l|}{ Autonomic nervous system } \\
\hline hypotension & 7.2 & 3.2 & a & NS \\
\hline syncope & 1.0 & 2.1 & a & NS \\
\hline tachycardia-palpitations & 11.3 & 7.5 & 0.80 & NS \\
\hline nasal congestion & 0.0 & 0.0 & - & NS \\
\hline dry mouth & 7.2 & 6.4 & 0.04 & NS \\
\hline increased salivation & 1.0 & 1.1 & a & NS \\
\hline blurred vision & 4.1 & 4.3 & a & NS \\
\hline nausea & 19.6 & 17.2 & 1.07 & NS \\
\hline vomiting & 5.1 & 4.3 & a & NS \\
\hline diarrhoea & 4.1 & 3.2 & a & NS \\
\hline constipation & 6.2 & 4.3 & a & NS \\
\hline urinary disturbances & 5.1 & 4.3 & a & NS \\
\hline others & 0.0 & 0.0 & a & NS \\
\hline \multicolumn{5}{|l|}{ Miscellaneous } \\
\hline dermatites-allergy & 1.0 & 1.1 & a & NS \\
\hline headache & 9.3 & 6.4 & 0.52 & NS \\
\hline dizziness & 13.4 & 3.2 & a & 0.01 \\
\hline weight gain, excessive & 1.0 & 3.2 & a & NS \\
\hline weight loss, excessive & 7.2 & 7.5 & 0.00 & NS \\
\hline others & 6.2 & 8.6 & 0.41 & NS \\
\hline
\end{tabular}

${ }^{a}$ Fisher's exact test

\section{Discussion}

The results of the present study show a better antidepressant efficacy of fluoxetine at a daily dose of $20 \mathrm{mg}$ as compared to milnacipran at a daily dose of $100 \mathrm{mg}$. Indeed, fluoxetine was found significantly superior to milnacipran on most rating instruments: MADRS including five individual items and the number of responders, Hamilton depression scale including ten individual items, CGI of severity of illness and therapeutical index, and global rating by the investigator. These clear differences in efficacy favoring fluoxetine over milnacipran were rather surprising. Indeed, previous studies have demonstrated the antidepressant activity of milnacipran as better than placebo (Macher et al. 1989) and equivalent to reference tricyclics such as amitriptyline (Ansseau et al. 1989a, b, 1991) or clomipramine (Clerc et al. 1990). The only published placebo-controlled study tested a fixed dose of milnacipran $100 \mathrm{mg}$ administered over a 5-week period in 58 major depressive inpatients exhibiting a score of at least 25 on the MADRS. Milnacipran was found more effective than placebo on all measures of depression already after 2 weeks: MADRS $(P=0.003)$, Hamilton depression scale $P=0.009)$, and Widlocher retardation scale $(P=0.04)$; moreover, the number of dropouts was higher in the placebo group $(72 \%)$ than in the milnacipran group $(24 \%)$. Therefore, this study showed that milnacipran $100 \mathrm{mg}$ daily was clearly effective among major depressive inpatients.

The therapeutic results of milnacipran in the present trial appear quite low in comparison with previous studies: $40 \%$ of treatment responders as compared to $64 \%$ in the milnacipran data base (Solles et al. 1991).

Three factors might explain the poor performance of milnacipran in the present study. First, the $100-\mathrm{mg}$ daily dose could have been selected below the optimal therapeutic dose for this sample of psychiatric outpatients. Previous studies in psychiatric inpatients showed that, as compared to amitriptyline $150 \mathrm{mg} / \mathrm{day}$, the latency of milnacipran $100 \mathrm{mg} /$ day was somewhat longer, with differences favoring amitriptyline after 2 weeks but disappearing 1 week later (Ansseau et al. 1989a). In contrast, milnacipran at a daily dose of $200 \mathrm{mg}$ demonstrated similar rapidity of improvement as amitriptyline $150 \mathrm{mg} /$ day (Ansseau et al. 1989b). Interestingly, the pooling of these two independent studies performed by the same group of investigators among psychiatric inpatients defined according to similar inclusion criteria revealed a clear doseresponse relationship, with milnacipran $200 \mathrm{mg}$ /day being significantly more effective than the lower doses 
(von Frenckell et al. 1990). The 100-mg daily dose was selected for the present study on the rationale that depressive outpatients would need a lower dose than depressive inpatients (Ansseau 1992). Indeed, depressive outpatients are generally characterized by a lower level of severity than depressive inpatients. In a recent study comparing the clinical characteristics of European depressive inpatients $(n=290)$ and outpatients $(n=183)$, von Frenckell et al. (1992) showed a significantly lower mean 17item Hamilton depression score among outpatients (25.5 versus $27.5, P=0.001$ ) with 6 items significantly higher among inpatients (suicide, initial insomnia, work and interest, retardation, psychic anxiety, and weight loss) and 2 items significantly higher among outpatients (agitation and loss of libido). It should be acknowledged, however, that controlled studies confirming that depressive outpatients require smaller doses than inpatients suffering from the same disease are lacking in the literature. Moreover, the severity of depressive symptomatology was very similar in the present trial and in previous trials among inpatients, with mean MADRS scores of, respectively, 33.5 in the present study and of 37.1 and 40.1 among inpatients (Ansseau et al. 1989a, b), suggesting that our hypothesis was probably false. It remains obvious that the optimal dose of milnacipran still needs to be clearly defined and it would have been more appropriate to establish it in regular dose-finding studies before comparing milnacipran with other antidepressants.

Second, milnacipran was given in one single daily dose in the present study whereas it was always administered in two divided daily doses in all previous trials. Since the plasma elimination half-life of milnacipran is about $7 \mathrm{~h}$ with only an inactive $n$-dealkylated metabolite (Puozzo et al. 1985), a single evening administration could lead to inadequate plasma levels. In contrast, the plasma half-life of fluoxetine is much longer (1-4 day) with norfluoxetine as an active metabolite with an even longer half-life (4-15 days), justifying a single daily dose (Benfield et al. 1986). Support for the once a day administration as the major factor in the poor performance of milnacipran can be found in a comparison with a previous study of our group using the same $100-\mathrm{mg}$ daily dose in two daily intakes (Ansseau et al. 1989a): the mean decrease in MADRS scores over a 4 -week period was $59.8 \%$ as compared to $30.2 \%$ in the present study.

Third, to a lesser extent, the lower severity of initial depressive symptomatology in the milnacipran group, as shown on the Hamilton depression scale and on the specific visual analogue scale, may have contributed to the limitation in treatment response. The higher number of passive aggressive personalities could also have played a role, even if the influence of axis II personality disorders on treatment response to antidepressants has never been specifically assessed previously.

In the present study, the clinical profile of milnacipran and fluoxetine appeared somewhat different. On the global visual analogue scales, fluoxetine showed significantly more psychostimulating activity than milnacipran. This finding, which confirms a previous evaluation using the same parameters (Ansseau et al. 1988), might explain why fluoxetine is particularly suitable for depressive outpatients, in whom sedation should generally be avoided.
In contrast, milnacipran seems characterized by a more "neutral" profile, as suggested in previous trials (Ansseau et al. 1989a, b, 1991; Macher et al. 1989; Clerc et al. 1990). The analysis of individual items of the MADRS and the Hamilton depression scale revealed, however, that the superiority of fluoxetine over milnacipran was also related to other depressive dimensions. Indeed, on the MADRS, they included apparent and expressed sadness, inner tension, sleep reduction and pessimistic thoughts, and on the Hamilton depression scale, items related to the anxiety/somatization (psychic anxiety, somatic anxiety, gastrointestinal symptoms), retardation (depressed mood, retardation, genital symptoms), and sleep disturbances (middle insomnia) factors, as defined by Guy (1976). Therefore, this study does not demonstrate that the profiles of milnacipran and fiuoxetine really differ, but that milnacipran is globally less effective.

In this study, the tolerance of milnacipran and fluoxetine was quite similar, with the exception of symptoms of dizziness which appeared more frequently with milnacipran. The majority of side-effects related to the gastrointestinal system. The incidence of nausea and vomiting with fluoxetine (respectively, $17.2 \%$ and $4.3 \%$ ) was rather similar to previous reports (Benfield et al. 1986). In contrast, the incidence of nausea and vomiting observed with milnacipran (respectively, 19.6\% and 5.1\%) was between 3 and 4 times higher than in previous studies with the same dose (Solles et al. 1991). This increased incidence is probably due to the administration of milnacipran in one single intake.

In conclusions, several methodological pitfalls prevent us to rule out the possibility that a balanced noradrenaline/serotonin reuptake inhibitor is superior to a selective serotonin reuptake inhibitor. A response to the respective role of the dose and the schedule of administration in the antidepressant activity of milnacipran should come from further comparative trials.

Acknowledgements. The authors would like to thank Drs. M.A. Gérard-Vandenhove, A. Lecoq, M. Spiers, S. Diricq, C. Dufour, S. Koch-Bourdouxhe, J. Mirel and P. Wuilmart, who participated to the study; M. von Frenckell-Spiertz who coordinated the data collection; Dr. A. Solles for her helpful comments on the manuscript; and $\mathrm{Ch}$. Gayetot for her secretarial assistance.

\section{References}

American Psychiatric Association (1987) Diagnostic and statistical manual of mental disorders, 3rd edn (revised). Washington, DC

Ansseau M (1992) The Atlantic gap: clinical trials in Europe and the United States. Biol Psychiatry31: 109-111

Ansseau M, Diricq St, Bataille M, Breulet M, Cerfontaine JL, Collard I, Coûteaux F, Dufrasne M, Fraipont J, Gernay P, Troisfontaines B, Bobon D (1985) Une physionomie comparée originale de l'activité clinique des antidépresseurs. Acta Psychiatr Belg 85:644-661

Ansseau M, Bataille M, Bobon D, Cerfontaine JL, Charles G, Coûteaux F, Diricq St, Fraipont J, Gernay P, Troisfontaines B (1988) Evaluation de l'activité clinique de la fluoxétine (Prozac) selon "les étoiles de Liège". Acta Psychiatr Belg 88:127-137

Ansseau M, von Frenckell R, Mertens C, De Wilde J, Botte L, Devoitille JM, Evrard JL, De Nayer A, Darimont P, Dejaiffe G, Mirel J, Meurice E, Parent M, Couzinier JP, Demarez JP, Serre 
C (1989a) Controlled comparison of two doses of milnacipran (F 2207) and amitriptyline in major depressive inpatients. Psychopharmacology $98: 163-168$

Ansseau M, von Frenckell R, Papart P, Mertens C, De Wilde J, Botte L, Devoitille JM, Evrard JL, De Nayer A, Koch-Bourdouxhe S, Darimont P, Lecoq A, Mirel J, Couzinier JP, Demarez JP, Serre C (1989b) Controlled comparison of milnacipran (F 2207) $200 \mathrm{mg}$ and amitriptyline in endogenous depressive inpatients. Hum Psychopharmacol 4:221-227

Ansseau M, von Frenckell R, Gérard MA, Mertens C, De Wilde J, Botte L, Devoitille JM, Evrard JL, De Nayer A, Darimont P, Mirel J, Troisfontaines B, Toussaint C, Couzinier JP, Demarez $J P$, Serre C (1991) Interest of a loading dose of milnacipran in endogenous depressive inpatients: comparison with the standard regimen and with fluvoxamine. Eur Neuropsychopharmacol $1: 113-121$

Benfield P, Ward A (1986) Fluvoxamine: a review of its pharmacodynamic and pharmacokinetic properties, and therapeutic eficacy in depressive illness. Drugs 32:313-334

Benfield P, Heel RC, Lewis SP (1986) Fluoxetine: a review of its pharmacodynamic and pharmacokinetic properties, and therapeutic efficacy in depressive illness. Drugs 32:481-508

Clerc G, Pagot R, Bouchard JM, Oules J, Guibert M, Amicot M, Guillard A, Cottin M, Dachary JM. Bezoury JP, Parmentier G, Gresle P, von Frenckell R, Serre C (1990) Intérêt thérapeutique du milnacipran et de la clomipramine au cours d'un traitement de 3 mois: résultats d'un essai comparatif. Psychiatr Psychobiol 5: $137-146$

Covi L, Lipman R, McNair DM, Czerlinski T (1979) Symptomatic volunteers in multicenter drug trials. Prog Neuropsychopharmacol 3:521-533

Guy W (ed) (1976) ECDEU Assessment manual for psychopharmacology (revised). National Institute of Mental Health, Psychopharmacology Research Branch, Rockville, MD

Hamilton M (1960) A rating scale for depression. J Neurol Neurosurg Psychiatry $12: 56-62$

Macher JP, Sichel JP, Serre C, von Frenckell R, Huck JC, Demarez JP (1989) Double-blind placebo-controlled study of milnacipran in hospitalized patients with major depressive disorders. Neuropsychobiology $22: 77-82$

Mathieu M (1990) New drug development: a regulatory overview. Parexel, Cambridge, MA
Ministère des Affaires Sociales et de l'Emploi, Ministère chargé de la Santé et de la Famille, Direction de la Pharmacie et du Médicament (1987) Bonnes pratiques cliniques. Avis aux promoteurs et aux investigateurs pour les essais cliniques des médicaments. Texte officiel en langue française. Paris, France

Montgomery A, Asberg M (1979) A new depression scale designed to be sensitive to change. Br J Psychiatry 134:382-389

Moret C, Charveron M, Finberg JPM, Couzinier JP, Briley M (1985) Biochemical profile of midalcipran (F 2207), 1-phenyl1-diethyl-aminocarbonyl-2-aminomethyl-cyclopropane (Z) hydrochloride, a potential fourth generation antidepressant drug. Neuropharmacology 24:1211-1219

Puozzo C, Filaquier C, Briley M (1985) Plasma levels of F 2207, midalcipran, a novel antidepressant, after single oral administration in volunteers. Br J Clin Pharmacol 20:291P-292P

Raskin A, Schulterbrandt J, Reatig N, Rice CE (1967) Factors of psychopathology in interview, ward behavior and self-report ratings of hospitalized depressions. J Consult Psychol 31: $270-278$

Schwartz D (1970) L'essai thérapeutique chez l'homme. Flammarion, Paris

Solles A, Serre C, Sutet P, Briley M (1991) Milnacipran: a potent antidepressant with combined NA and 5-HT mechanism of action. In: Ansseau M, von Frenckell R, Franck G (eds) Biological markers of depression: state of the art. Excerpta Medica, Amsterdam, pp 197-202

Van Praag HM (1980a) Central monoamine metabolism in depressions. I. Serotonin and related compounds. Compr Psychiatry $21: 30-43$

Van Praag HM (1980b) Central monoamine metabolism in depressions. 11. Catecholamines and related compounds. Compr Psychiatry $21: 44-54$

Van Praag HM (1984) Studies in the mechanism of action of serotonin precursors in depression. Psychopharmacol Bull $20: 599-602$

von Frenckell R, Ansseau, M, Serre C, Sutet P (1990) Pooling two controlled comparisons of milnacipran (F 2207) and amitriptyline in endogenous inpatients. Int Clin Psychopharmacol 5:49-56

von Frenckell R, Cheuvart B, Gratton R, Copp J, Gammans R, Vanbrabant E (1992) Clinical trials of antidepressants in the US and in Europe. The Atlantic gap. Clin Neuropharmacol 15 [suppl 1]: 516B 